http://jmscr.igmpublication.org/home/ ISSN (e)-2347-176x ISSN (p) 2455-0450

crossref DOI: https://dx.doi.org/10.18535/jmscr/v8i1.174

Journal Of Medical Science And Clinical Research

\title{
Study of BISAP Score in Evaluation of Acute Pancreatitis and Its Severity
}

\author{
Authors \\ Dr Balaji Chittipotula ${ }^{1^{*}}$, Dr Mahesh Babu $\mathrm{Ch}^{2}$, Dr S V Satyanarayana Rao $^{3}$, \\ Dr P Ashok Teja ${ }^{4}$ \\ ${ }^{1}$ Postgraduate, Department of General Surgery, GEMS, Srikakulam \\ ${ }^{2}$ Sr.Resident, Department of Urology, Baby Memorial Hospital, Kozhikode \\ ${ }^{3}$ Professor, Department of General Surgery, GEMS. \\ ${ }^{4}$ Postgraduate, Department of General Surgery, GEMS, Srikakulam \\ *Corresponding Author \\ Dr Balaji Chittipotula
}

\begin{abstract}
Back ground: Multiple risk stratification tools for acute pancreatitis have been developed, but their clinical usefulness is limited. In Ranson's criteria and modified Glasgow score there are multiple parameters, of which some of them are not available in majority of hospitals in India. In addition, both are assessed after $48 \mathrm{hrs}$, thereby missing potentially valuable early therapeutic window. The APACHE II score requires collection of large number of parameters some of which may not be relevant to prognosis. For this purpose, a simple and accurate clinical scoring system that is, Bedside Index for Severity in Acute Pancreatitis (BISAP) scoring system was developed. This scoring system is used for stratifying patients according to their risk of mortality and is able to identify patients at increased risk of mortality prior to the onset of organ failure. More over the data for BISAP score is collected within the first 24hrs of hospitalization. The ability to stratify patients early in their course is a major step in improving future management strategies in acute pancreatitis.

Materials and Methods: 50 patients admitted from November 2017 to January 2019 with acute pancreatitis were included in the study. BISAP score was calculated in all such patients, based on the data obtained within 24hrs of hospitalization. Patients were assessed for organ failure according to Marshall scoring system and followed throughout hospitalization for assessment of complications. Statistical analyses were made using Fischer's exact probability test. The difference was assumed statistically significant when $p<0.05$.

Results: There was a statistically highly significant trend for increasing mortality $(p<0.05)$ and intermediate markers of severity $(p<0.05)$ that is transient organ failure, persistent organ failure and pancreatic necrosis with BISAP score $\geq 3$.

Conclusion: The BISAP score represents a simple way to identify patients at risk of increased mortality and the development of intermediate markers of severity within 24 hours of presentation.
\end{abstract}

\section{Introduction}

Acute pancreatitis is defined as an inflammatory process of the pancreas with possible peripancreatic tissue and multi-organ involvement inducing Multi-Organ Dysfunction Syndrome (MODS) with an increased mortality rate ${ }^{1}$.

Acute pancreatitis may be categorized as mild or severe. Mild acute pancreatitis is characterized by interstitial edema of the gland and minimal organ 
dysfunction. Severe acute pancreatitis is characterized by pancreatic necrosis, severe systemic inflammatory response and often multiorgan failure. $80 \%$ of patients have mild attack of pancreatitis, the mortality rate is around $1 \%$. In those who have a severe attack of pancreatitis, the mortality rate varies from $20 \%$ to $50 \%$. About one-third of deaths occur in the early phase of attack, from multiorgan failure, while deaths occurring after first week of onset are due to septic complications. Most patients of acute pancreatitis recover without complications, the overall mortality rate of this illness is between 2$5 \%$. Multiple risk stratification tools for acute pancreatitis have been developed, but their clinical usefulness is limited. In Ranson's criteria ${ }^{4}$ and modified Glasgow score there are multiple parameters, of which some of them are not available in majority of hospitals in India. In addition, both are assessed after $48 \mathrm{hrs}$, thereby missing potentially valuable early therapeutic window. The APACHE $\mathrm{II}^{5,6}$ score (Acute Physiology and Chronic Health Evaluation) is the most widely used prediction system currently, but it requires the collection of large number of parameters some of which may not be relevant to prognosis. APACHE II was originally developed as an intensive care instrument. For this purpose, a simple and accurate clinical scoring system that is, Bedside Index for Severity in Acute Pancreatitis (BISAP) scoring system was developed. This scoring system is used for stratifying patients according to their risk of mortality and is able to identify patients at increased risk of mortality prior to the onset of organ failure. More over the data for BISAP score is collected within the first $24 \mathrm{hrs}$ of hospitalization. The ability to stratify patients early in their course is a major step in improving future management strategies in acute pancreatitis.

\section{BISAP Score}

1. Blood urea nitrogen $>25 \mathrm{mg} / \mathrm{dl}$,

2. Impaired mental status (Glasgow coma scale score $<15$ ),
3. Systemic inflammatory response syndrome (Presence of $\geq 2$ of following criteria)

- Pulse rate $>90 /$ minute,

- Respiratory rate $>20 / \mathrm{min}$ or $\mathrm{PaC0} 2<$ $32 \mathrm{~mm} \mathrm{Hg}$-Temperature $>38$ or $<36$ degree Celsius,

- WBC count > 12000 or < 4000 cells/cubic $\mathrm{mm}$ or $>10 \%$ immature neutrophils,

4. Age $>60$ years,

5. Pleural effusion (on CT scan or chest $\mathrm{x}$ ray or USG).

Each point on BISAP score is worth 1 point.

\section{Aim of the study}

To prospectively evaluate the ability of the Bedside Index for Severity in Acute Pancreatitis (BISAP) score to predict mortality as well as intermediate markers of severity.

\section{Methodology \\ Source of Data}

The material of study comprised of 50 patients who presented to GEMS and Hospital with Acute Pancreatitis from November 2017 to January 2019were included. BISAP score is calculated in all such patients based on data obtained within 24hours of Hospitalization.

\section{Method of Data Collection}

After admission BISAP score is calculated in all such patients based on data obtained within $24 \mathrm{hr}$ of Hospitalization that includes individual components of the BISAP scoring system which is obtained through clinical evaluation, biochemical and pathological evaluation, chest $\mathrm{x}$ ray, CT, MRI, USG of the abdomen.

\section{Statistical Analysis}

Discrimination of the BISAP score for predicting mortality will be evaluated in the prospective cohort, using Fischer's Exact Test.

A "P" value $<0.05$ was noted to be significant for all tests given the multiple testings conducted among the study cohort. Data analysis was carried out using SPSS (Statistical Package for the Social Sciences) package. 


\section{Inclusion Criteria}

All cases of acute pancreatitis patients who presented to GEMS and Hospital from November 2017 to January 2019.

\section{Exclusion Criteria}

Acute Pancreatitis patients, presenting with organ failure at the time of admission (or) within 24hours of presentation.

\section{Results}

\section{Age Distribution}

Table 1: Distribution of Age among study population

\begin{tabular}{|l|c|c|}
\hline $\begin{array}{l}\text { Age } \\
\text { (Years) }\end{array}$ & No of Cases & $\begin{array}{c}\text { Percentage } \\
(\%)\end{array}$ \\
\hline $21-30$ & 13 & $26 \%$ \\
\hline $31-40$ & 19 & $38 \%$ \\
\hline $41-50$ & 4 & $8 \%$ \\
\hline $51-60$ & 4 & $8 \%$ \\
\hline $61-70$ & 10 & $20 \%$ \\
\hline
\end{tabular}

\section{Complications}

Out of 50 cases, 11 cases developed organ failure. Among these 11 cases, 9 cases had a BISAP Score $\geq 3$ and 2 cases had a BISAP Score of $<3.6$ cases had Renal Failure, 3 had ARDS, 1 had Cardiac Failure and 1 case suffered from MODS.

Table 2: Distribution of organ failure among study population

\begin{tabular}{|l|c|c|c|}
\hline $\begin{array}{l}\text { Organ } \\
\text { Failure }\end{array}$ & BISAP $\geq \mathbf{3}$ & BISAP $<\mathbf{3}$ & Total \\
\hline RENAL & $5(10 \%)$ & $1(2 \%)$ & $6(12 \%)$ \\
\hline ARDS & $2(4 \%)$ & $1(2 \%)$ & $3(6 \%)$ \\
\hline CARDIAC & $1(2 \%)$ & 0 & $1(2 \%)$ \\
\hline MODS & $1(2 \%)$ & 0 & $1(2 \%)$ \\
\hline
\end{tabular}

\section{Organ Failure}

Out of 50individuals, 39 (78\%) had no organ failure, remaining 11(22\%) developed organ failure. Among these11 individuals, 9 had BISAP score $\geq 3$ and 2 had BISAP score $<3$.

Table 3: Distribution of Organ Failure according to BISAP Score

\begin{tabular}{|l|c|c|c|}
\hline Organ Failure & BISAP $\geq \mathbf{3}$ & BISAP $<\mathbf{3}$ & Total \\
\hline No & $9(18 \%)$ & $30(60 \%)$ & $39(78 \%)$ \\
\hline Yes & $9(18 \%)$ & $2(4 \%)$ & $11(22 \%)$ \\
\hline
\end{tabular}

Using Fischer's exact test, $\mathrm{p}$ value was calculated and found to be significant $(p<0.0007)$.

\section{Transient organ failure}

Out of 50individuals, 11 had organ failure in which 7 had transient organ failure. All had BISAP score $\geq 3$ except 2 individuals who had BISAP score of $<3$. All these patients recovered without any mortality.

Table 4: Distribution of Transient organ failure among study population according to BISAP Score

\begin{tabular}{|l|c|c|}
\hline $\begin{array}{l}\text { Transient organ } \\
\text { failure }\end{array}$ & BISAP $\geq \mathbf{3}$ & BISAP $<3$ \\
\hline No & $\mathbf{1 3}(\mathbf{2 6 \%})$ & $\mathbf{3 0}(\mathbf{6 0 \%} \%)$ \\
\hline Yes & $\mathbf{5 ( 1 0 \% )}$ & $\mathbf{2 ( 4 \% )}$ \\
\hline
\end{tabular}

Fischer's exact test was done and $\mathrm{p}$ value was found to be significant ( $\mathrm{p}<0.006)$.

\section{Persistent organ Failure}

Out of 50 individuals, 4 individuals developed Persistent Organ Failure. All these 4 had BISAP score $>3$.

Table 5: Persistent organ failure among study population according to BISAP Score

\begin{tabular}{|l|c|c|}
\hline $\begin{array}{l}\text { Persistent organ } \\
\text { failure }\end{array}$ & BISAP $\geq 3$ & BISAP $<3$ \\
\hline No & $14(28 \%)$ & $32(64 \%)$ \\
\hline Yes & $4(8 \%)$ & 0 \\
\hline
\end{tabular}

Fischer's exact test was done and $\mathrm{p}$ value found to be significant $(\mathrm{p}=0.0133)$.

\section{Mortality}

3 individuals in the present study died $(6 \%)$ and they all had BISAP score $>3$. Out of 3, 2 patients had ARDS and 1 patient developed MODS.

Table 6: Mortality among study population

\begin{tabular}{|l|c|c|}
\hline Mortality & No of cases & Percentage (\%) \\
\hline No & 47 & $94 \%$ \\
\hline Yes & 3 & $6 \%$ \\
\hline
\end{tabular}

Table 7: Distribution of Mortality among study population according to BISAP Score

\begin{tabular}{|l|c|c|}
\hline Core & Cases & Mortality \\
\hline BISAP 0 & 0 & 0 \\
\hline BISAP 1 & $3(6 \%)$ & 0 \\
\hline BISAP 2 & $29(58 \%)$ & 0 \\
\hline BISAP 3 & $12(24 \%)$ & 0 \\
\hline BISAP 4 & $5(10 \%)$ & $2(40 \%)$ \\
\hline BISAP 5 & $1(2 \%)$ & $1(100 \%)$ \\
\hline
\end{tabular}

Using Fischer's exact test, "p" value was calculated and found to be significant $(\mathrm{p}<0.05)$. 


\section{Severity}

The severity of Acute Pancreatitis was defined on the basis of BISAP score. Out of 50 individuals 18 (36\%) had severe pancreatitis and 32 (64\%) were classified as having mild pancreatitis.

Table - 8: Distribution of severity among Study Population according to BISAP score

\begin{tabular}{|l|c|c|}
\hline Score & No of cases & Percentage (\%) \\
\hline BISAP $\geq 3$ & 18 & $36 \%$ \\
\hline BISAP $<3$ & 32 & $64 \%$ \\
\hline
\end{tabular}

\section{Hospital Stay}

Table 9: Hospital Stay among Study Population

\begin{tabular}{|l|c|c|}
\hline Hospital stay & $\begin{array}{c}\text { Mild Pancreatitis } \\
(<3)\end{array}$ & $\begin{array}{c}\text { Severe } \\
\text { Pancreatitis }(\geq 3)\end{array}$ \\
\hline Range (in days) & $\mathbf{2 - 8}$ & $\mathbf{4 - 1 4}$ \\
\hline Mean (in days) & $\mathbf{4 . 8}$ & $\mathbf{8 . 3}$ \\
\hline
\end{tabular}

The duration of hospital stay increases with increasing BISAP score. Mean duration Hospital stay was 4.8 days for mild acute pancreatitis and 8.3 days for severe acute pancreatitis.

\section{Pancreatic Necrosis according to BISAP score}

Out of 50 individuals, $7(14 \%)$ developed pancreatic necrosis. Among these 7, 6 had BISAP score $\geq 3$ and 1 had BISAP score $<3$.

Table -10: Distribution of Pancreatic Necrosis among study group according to BISAP score

\begin{tabular}{|l|c|c|}
\hline P.Necrosis & BISAP $\geq \mathbf{3}$ & BISAP $<\mathbf{3}$ \\
\hline Yes & $6(12 \%)$ & $1(2 \%)$ \\
\hline No & $12(24 \%)$ & $31(62 \%)$ \\
\hline Total & $18(36 \%)$ & $32(64 \%)$ \\
\hline
\end{tabular}

Fischer's exact test was done and $p$ value found to be significant $(\mathrm{p}=0.0063)$

\section{Discussion}

Acute pancreatitis remains a serious disease, in spite of advances in the medical field. The majority of patients present with a mild disease, however approximately $20 \%$ pass through a severe course and require appropriate management, in an intensive care unit. In the present study severity of acute pancreatitis is defined on the basis of BISAP Score.

\begin{tabular}{|l|c|}
\hline Mild AP BISAP Score & $<3$, \\
\hline Severe AP BISAP Score & $\geq 3$ \\
\hline
\end{tabular}

Multi-organ dysfunction syndrome, the extent of pancreatic necrosis, local infection and sepsis are the major determinants of mortality in $\mathrm{AP}^{4-6}$.

Pancreatic necrosis is considered as a potential risk for infection, necrosis superadded with infection represents the primary cause of late mortality. Occurrence of Acute Respiratory Distress Syndrome (ARDS), cardiovascular failure (CVF), Acute Kidney Injury can predict the fatal outcome in Severe Acute Pancreatitis $(\mathrm{SAP})^{7}$. A wide range of mortality $(20 \%-60 \%)$ has been reported in patients suffering from Severe Acute Pancreatitis (SAP) $)^{7,9}$. Early diagnosis, prognostic evaluation and effective treatment are extremely important in reducing the morbidity and mortality associated with Severe Acute Pancreatitis (SAP).

On account of differences in outcome, between the patients with mild and severe disease, it is important to define that group of patients, who will develop severe pancreatitis, predicting which still represents challenge for the clinician.

Interestingly, most patients do not exhibit Multi Organ Dysfunction Syndrome (MODS) during the early phase of the disease i.e. within 12-24 hrs of acute pancreatitis. Multi Organ Dysfunction Syndrome (MODS) usually sets in during $2^{\text {nd }}$ to $3^{\text {rd }}$ day of severe acute pancreatitis.

Identification of patients at risk for mortality early in the course of acute pancreatitis is an important step in improving outcome" write Dr.Wu B U ${ }^{7}$ and his colleagues, from Brigham and women's hospital and Harvard medical school in Boston, Massachusetts (USA). Current methods of risk stratification in acute pancreatitis have important limitations. Most patients of acute pancreatitis recover without complications, the overall mortality rate of this illness is between $2-5 \%^{2,3}$. Multiple risk stratification tools for acute pancreatitis have been developed, but their clinical usefulness is limited. Older measures such as, the Ranson's criteria and modified Glasgow score use data that are not routinely collected at the time of hospitalization. In most of the patient's analysis of the above criteria is helpful beyond 48 hours after 
onset on the disease thereby missing potentially valuable early therapeutic window. The APACHE II $^{5,6}$ score is the most widely used prediction system currently but it requires the collection of large number of parameters. APACHE II was originally developed as an intensive care instrument and requires the collection of large number of parameters, some of which may not be relevant to prognosis.

For this purpose a simple and accurate clinical scoring system that is bedside index for severity in acute pancreatitis (BISAP) scoring system ${ }^{7}$ was developed. This scoring system is used for stratifying patients according to their risk of hospital mortality and is able to identify patients at increased risk of mortality prior to the onset of organ failure. Data for BISAP scoreis collected within the first $24 \mathrm{hrs}$ of hospitalization. The ability to stratify patients early in the course of the disease is a major step in improving management strategies in Acute Pancreatitis.

\section{Statistical Analysis of the Observed Data}

Age

The mean age of presentation in the present study is 41.7 years and is comparable to study done by Choudhuri $\mathrm{G}$ et $\mathrm{al}^{38}$. $19(38 \%)$ cases present between the age group of $31-40$ yrs. This is because alcohol was the main etiology in the present study group which presents usually in the younger age group.

Table 11: Comparison of age

\begin{tabular}{|l|c|c|c|c|c|}
\hline $\begin{array}{l}\text { Name of } \\
\text { Study }\end{array}$ & $\begin{array}{c}\text { Kashid A } \\
\text { et } \mathbf{~ a l ~}^{\mathbf{3 7}}\end{array}$ & $\begin{array}{c}\text { Choudhuri } \\
\mathbf{G ~ e t ~ a ~}^{\mathbf{3 8}}\end{array}$ & $\begin{array}{c}\text { Pupelis G } \\
\text { et } \mathbf{~ a l}^{\mathbf{3 9}}\end{array}$ & $\begin{array}{c}\text { Buchler } \\
\text { MW et al }\end{array}$ & $\begin{array}{c}\text { Present } \\
\text { study }^{\mathbf{4}}\end{array}$ \\
\hline Age in years & 35 & 44.89 & 47 & 55.1 & 41.7 \\
\hline
\end{tabular}

\section{Severity}

Severity of acute pancreatitis was defined on the basis of BISAP Score. From the study group of 50 individuals, $18(36 \%)$ had severe acute pancreatitis that is, a BISAP Score of more than or equal to 3 and $32(64 \%)$ were classified as having mild pancreatitis that is, a BISAP Score of $<3$.

Table 12: Comparison of Severity

\begin{tabular}{|c|c|c|c|}
\hline Severity & $\begin{array}{c}\text { Kashid A } \\
\text { et }^{\mathbf{3 7}}\end{array}$ & $\begin{array}{c}\text { Choudhuri } \\
\text { G et al }^{38}\end{array}$ & $\begin{array}{c}\text { Buchler } \\
\text { MW et al }\end{array}$ \\
\hline Mild disease $(\%)$ & 52.73 & 47.7 & 58 \\
\hline Severe disease $(\%)$ & 47.27 & 52.3 & 42 \\
\hline
\end{tabular}

Severity of acute pancreatitis in the present study is comparable to above studies.

Table 13: Comparison of severity according to BISAP Score

\begin{tabular}{|l|c|c|c|}
\hline Severity & BISAP Score & No. of Individuals & Percentage(\%) \\
\hline Mild Acute Pancreatitis & $<3$ & 32 & 64 \\
\hline SevereAcute Pancreatitis & $\geq 3$ & 18 & 36 \\
\hline
\end{tabular}

\section{Duration of Hospital Stay}

The mean duration of hospital stay in mild pancreatitis (BISAP Score<3) was 4.8 days and severe acute pancreatitis was 8.3 days. In the

Table 14: Duration of Hospital stay

\begin{tabular}{|l|c|c|}
\hline Hospital Stay & $\begin{array}{c}\text { Mild Pancreatitis } \\
\text { BISAP score }<\mathbf{3}\end{array}$ & $\begin{array}{c}\text { Severe Acute Pancreatitis } \\
\text { BISAP score } \geq \mathbf{3}\end{array}$ \\
\hline RANGE(in days) & $2-8$ & $4-14$ \\
\hline MEAN(in days) & 4.8 & 8.3 \\
\hline
\end{tabular}




\section{Organ Failure}

In the present study, out of 50 individuals $39(78 \%)$ had no evidence of any organ failure, whereas $11(22 \%)$ individuals developed one or more organ failure. Out of these individuals $7(63.63 \%)$ individuals had transient organ failure and $4(36.36 \%)$ had persistent organ failure. In transient organ failure group, 6 individuals had transient acute kidney injury. The results noticed in our study group were equivalent to the study done by Vikesh $\mathrm{K}$ et al. ${ }^{8}$

Table 15: Comparison of Organ Failure

\begin{tabular}{|l|c|c|c|c|c|}
\hline & $\begin{array}{c}\text { Total number } \\
\text { of patients }\end{array}$ & $\begin{array}{c}\text { No organ } \\
\text { failure }\end{array}$ & $\begin{array}{c}\text { Organ } \\
\text { failure }\end{array}$ & $\begin{array}{c}\text { Transient organ } \\
\text { failure }\end{array}$ & $\begin{array}{c}\text { Persistent organ } \\
\text { failure }\end{array}$ \\
\hline $\begin{array}{l}\text { Vikesh K Singh } \\
\text { et al }^{8}\end{array}$ & 397 & $325(82 \%)$ & $72(18 \%)$ & $53(74 \%)$ & $19(26 \%)$ \\
\hline Present study & 50 & $39(78 \%)$ & $11(22 \%)$ & $7(63.6 \%)$ & $4(36.6 \%)$ \\
\hline
\end{tabular}

Out of 50 individuals in the present study $7(14 \%)$ individuals developed pancreatic necrosis, evidenced on radiological imaging using $\mathrm{CT}$ scan. In those 7 individuals, 6(85.7\%) individuals had a BISAP score of more than 3 and $1(14.3 \%)$ had a BISAP Score of less than 3.

\section{Mortality}

Out of 50 individuals we had 3 fatalities accounting to $6 \%$ overall mortality rate and $16.6 \%$ of mortality rate among individuals suffering from severe acute pancreatitis that is, BISAP Score $\geq 3$ compared to none in the individuals who present with BISAP Score $<3$ which is equivalent to the study done by Vikesh K Singh. ${ }^{8}$ Out of 3 fatalities, all 3 were male.

Table 16: Comparison of Mortality

\begin{tabular}{|l|c|c|}
\hline Study Group & $\begin{array}{c}\text { Mortality with } \\
\text { BISAP score } \geq \mathbf{3 ( \% )}\end{array}$ & $\begin{array}{c}\text { Mortality with } \\
\text { BISAP } \\
\text { score }<\mathbf{3}(\%)\end{array}$ \\
\hline $\begin{array}{l}\text { Vikesh K Singh et } \\
\mathrm{al}^{8}\end{array}$ & $18 \%$ & $1 \%$ \\
\hline $\begin{array}{l}\mathrm{Wu} \text { BU,Johannes et } \\
\mathrm{al}^{7}\end{array}$ & $>20 \%$ & $<1 \%$ \\
\hline Present study & $16 \%$ & none \\
\hline
\end{tabular}

\section{Conclusion}

\section{Prediction of mortality}

The BISAP score is a simple and accurate method for the early identification of patients at increased risk for in hospital mortality

\section{Prediction of intermediate markers of severity}

The BISAP score represents a simple way to identify patients at risk of the development of intermediate markers of severity within $24 \mathrm{~h}$ of presentation.

\section{References}

1. Bradley EL $3^{\text {rd }}$ a clinically based classification system for acute pancreatitis. Summary of the International Symposium on Acute Pancreatitis, Atlanta, Ga, September 11 through 13, 1992. arch. 1993; 128:586-590.

2. Fagenholz PJ, Castillo CF, Harris NS, et al. Increasing United States hospital admissions for acute pancreatitis, 19882003. AnnEpidermiol2007;17:491-7.

3. PA, Freeman ML, Practice guidelines in acute pancreatitis. Am J Gastroenterol 2006; 101:2379-400.

4. Ranson JH, Rifkind KM, Roses DF, et al. objective early identification of severe acute pancreatitis. Am J Gastroenterol 1974; 61:443-51.

5. Yeung YP, Lam BY, Yip AW.APACHE system is better than Ranson system in the prediction of severity of acute pancreatitis. Hepatobiliary pancreat Dis Int 2006; 5:294-9.

6. Larvin M, McMahon MJ APACHE-II score for assessment and monitoring of acute pancreatitis. Lancet 1989; 2:201-5.

7. Wu BU, Johannes RS, Sun $X$ et al.The early prediction of mortality in acute Pancreatitis: a large population-based study. Gut 2008; 57: 1698 - 703.

8. Vikesh K. Singh et al. A prospective evaluation of the bedside index for severity in acute pancreatitis score in 
assessing mortality and intermediate markers of severity in acute pancreatitis am J Gastroenterol 2009; 104:966-971.

9. Bradley EL. A clinical based classification system for acute pancreatitis. Areh Surg 1993; 128: 586-590. 